\title{
Deterioration Mechanism for Tea Infusion Aroma by Retort Pasteurization
}

\author{
Hitoshi Kinugasa and Tadakazu TaKeo \\ ITO-EN Co., Ltd., Central Research Institute, Sagara-cho, \\ Haibara-gun, Shizuoka 421-05, Japan \\ Received February 6, 1990
}

\begin{abstract}
After retort pasteurization, the change in the aroma pattern of green, oolong and black tea drinks was investigated.

By pasteurization, such volatile compounds as leaf alcohol and its esters had deteriorated. Others such as linalool and geraniol were liberated from non-volatile precursors. It was revealed that such changes in the aroma compounds destroy the aroma balance of each tea drink, causing the off-flavor called retort smell.

From enzymatic experiments, it was clarified that the precursors of mono-terpene alcohols induced during pasteurization are those water-soluble glucosides dissolved in the green tea extract.
\end{abstract}

At the present time, canned tea extract infusions (green, oolong and black tea) are very popular drinks in Japan. About $500,000 \mathrm{kl}$ of these types of drinks were consumed in 1988.

In the production of tea drinks, the deterioration of tea flavor is an extremely important problem, and improvements to the flavor of tea drinks has become improtant. Especially, the retort smell produced during retort pasteurization seriously effects the flavor of tea drinks.

In this paper, changes of the aroma compounds found in tea drinks after retort pasteurization were surveyed by using the gas-chromatography technique. Furthermore, the formation mechanism for the retort aroma in tea drinks was also studied.

\section{Experimental}

1. Production process for a canned tea drink. Tea $(1 \mathrm{~g} / 100 \mathrm{ml})$ was extracted with hot distilled water at $80^{\circ} \mathrm{C}$ for $2 \mathrm{~min}$. The tea extract was adjusted to $\mathrm{pH} 6.0$ by $\mathrm{NaHCO}_{3}$ after adding ascorbate as an antioxidant, before the tea infusion was warmed to $93^{\circ} \mathrm{C}$ and canned. The canned tea infusion was pasteurized for $8 \mathrm{~min}$ at $120^{\circ} \mathrm{C}$.

2. Preparation of the tea aroma fraction from tea drink. A tea infusion (1 1) was distilled by steam distillation at $30-40^{\circ} \mathrm{C}$ under $30 \mathrm{~mm}$ of $\mathrm{Hg}$ for $120 \mathrm{~min}$. Before the distillation, $50 \mu \mathrm{g}$ of ethyldecanoate was added to the tea infusion as an internal standard for determining the relative amount of each tea aroma compound. After distillation, the tea aroma fraction in the distillate was extracted by ether. The ether extract was dried by $\mathrm{Na}_{2} \mathrm{SO}_{4}$ and concentrated to $50 \mathrm{mg}$.

3. Identification and determination of the tea aroma compounds. Each tea aroma compound was identified by a GS-MS analysis using a Hitachi-M-80A GC-MS instrument (ionization voltage, $20 \mathrm{eV}$; electron current, $110 \mu \mathrm{A}$; ion acceleration voltage, $3 \mathrm{kV}$; column, PEG $20 \mathrm{M}$, $0.35 \mathrm{~mm} \times 50 \mathrm{~m}$; temp., $60-200^{\circ} \mathrm{C}, 2^{\circ} \mathrm{C} / \mathrm{min}$ ). The spectral data was compared with the data for authentic compounds and those previously reported, ${ }^{1,2)}$ and the retention time on the gas-chromatogram was compared with that of authentic compounds. The relative amount of each compound is shown by the ratio of the peak area of each compound to that of the internal standard on the gas-chromatogram.

4. Effect of pasteurization conditions on canned tea drink flavor. Pasteurizing was done for $5,10,15$ and $20 \mathrm{~min}$ at $100,115,120$ and $125^{\circ} \mathrm{C}$. The changes in the content of tea aroma compounds in each pasteurized sample were investigated.

5. Investigation of the formation mechanism for retort smell. The amounts of aroma compounds in a tea infusion extracted from $10 \mathrm{~g}$ of tea were determined before and after incubating for $16 \mathrm{hr}$ at $38^{\circ} \mathrm{C}$ with $10 \mathrm{mg}$ of pectinase (EC 3.1.1.11 from tomato, Sigma). ${ }^{3)}$ The inhibitory effects of 
$\mathrm{Hg}^{2+}$ and $\mathrm{CN}^{-1}$ on the aroma formation by pectinase were surveyed by adding these inhibitors to the reaction mixture.

\section{Results}

1. Changes in the tea aroma pattern after retort pasteurization

As shown in Table I, almost all the volatile compounds in the oolong tea and black tea infusions decreased after retort pasteurization. However, some volatile compounds such as terpene alcohols and its oxides, benzyl alcohol, $\beta$-ionone, $(Z)$-jasmone and indole, increased distinctly in the green tea infusion after pateurization.

After retort pasteurization, the green tea drink had a strong off-flavor aroma which we call the retort smell. Black tea and oolong tea drinks lost their fresh and flowery aroma, this being especially marked for black tea. ${ }^{4)}$

\section{Quantitative changes in the tea aroma} compounds by retort pasteurization

In Fig. 1, the quantitative changes in linalool, geraniol, 4-vinylphenol and indole found in the green tea drink aroma are shown under different conditions.

The amounts of these compounds increased only after pasteurization for a long period $(20 \mathrm{~min})$ at $100^{\circ} \mathrm{C}$, as is shown for linalool and geraniol. However, the quantitative changes in those compounds were induced immediately at $125^{\circ} \mathrm{C}$, and the induced amounts of those compounds reached maximum levels after $10 \mathrm{~min}$.

Table I. Changes in Tea Aroma Compounds in Green, Oolong and Black TEA INFUSIONS BEFORE AND AFTER RETORT PASTEURIZATION

\begin{tabular}{|c|c|c|c|c|c|c|}
\hline \multirow{2}{*}{$\begin{array}{c}\text { Tea } \\
\text { compound }\end{array}$} & \multicolumn{2}{|c|}{ Green tea } & \multicolumn{2}{|c|}{ Oolong tea } & \multicolumn{2}{|c|}{ Black tea } \\
\hline & Before & After & Before & After & Before & After \\
\hline Hexanal & 0.015 & Trace & 0.569 & 0.084 & 0.370 & 0.163 \\
\hline 1-Penten-3-ol & 0.352 & 0.740 & 0.890 & Trace & 0.089 & 0.202 \\
\hline (E)-2-Hexanal & 0.231 & Trace & 0.164 & Trace & 1.462 & 0.490 \\
\hline (Z)-2-Penten-1-ol & - & - & 0.590 & 0.069 & 0.342 & 0.283 \\
\hline 6-Methyl-5-hepten-2-on & - & - & 0.177 & Trace & 1.991 & 1.325 \\
\hline (Z)-3-Hexenol & 0.129 & Trace & 0.118 & Trace & 0.494 & 0.414 \\
\hline Linalooloxide I & 0.064 & 0.132 & 0.244 & 0.134 & 1.494 & 1.134 \\
\hline Linalooloxide II & 0.131 & 0.359 & 0.075 & Trace & 0.375 & 1.013 \\
\hline$(E, E)$-2,3-Heptadienal & 0.253 & 0.753 & 0.508 & 0.476 & 0.254 & 0.731 \\
\hline Benzaldehyde & 0.225 & 0.128 & 0.562 & 0.092 & 0.300 & 0.248 \\
\hline Linalool & 0.525 & 0.710 & 0.363 & 0.103 & 2.106 & 2.004 \\
\hline 3,7-Dimethyl-1,5,7-octatrien-3-ol & - & - & 0.463 & 0.116 & - & - \\
\hline (Z)-3-Hexenylhexanoate & 0.108 & Trace & 0.032 & Trace & 0.257 & Trace \\
\hline$(\alpha)$-Terpineol & - & 一 & 0.172 & Trace & 0.365 & Trace \\
\hline Linalooloxide III & 0.126 & 0.236 & 0.072 & Trace & - & - \\
\hline Methyl salicylate & - & - & 0.179 & 0.107 & 1.395 & 0.721 \\
\hline Geraniol & 0.171 & 0.354 & 0.159 & 0.081 & 1.957 & 1.222 \\
\hline Benzyl alcohol & 0.153 & 0.740 & 0.590 & 0.090 & 0.121 & 0.527 \\
\hline 2-Phenylethanol & 0.320 & 0.119 & 0.072 & Trace & - & - \\
\hline$\beta$-Ionone $+(Z)$-Jasmone & 0.640 & 2.861 & 0.607 & 1.656 & 2.338 & 3.124 \\
\hline Nerolidol & 1.342 & Trace & 2.894 & 0.083 & 0.310 & 0.195 \\
\hline Jasminelactone & - & - & 0.084 & Trace & - & - \\
\hline 4-Vinylphenol & - & 0.710 & - & - & - & - \\
\hline Indole & 0.170 & 0.971 & 0.190 & Trace & - & - \\
\hline
\end{tabular}

The samples for the assay of aroma comounds were prepared from the same tea infusion before and after retort pasteurization.

The relative amounts of aroma compounds are shown as the ratio of peak area of each compound to that of an internal standard (ethyl decanoate) on the gas-chromatogram. 


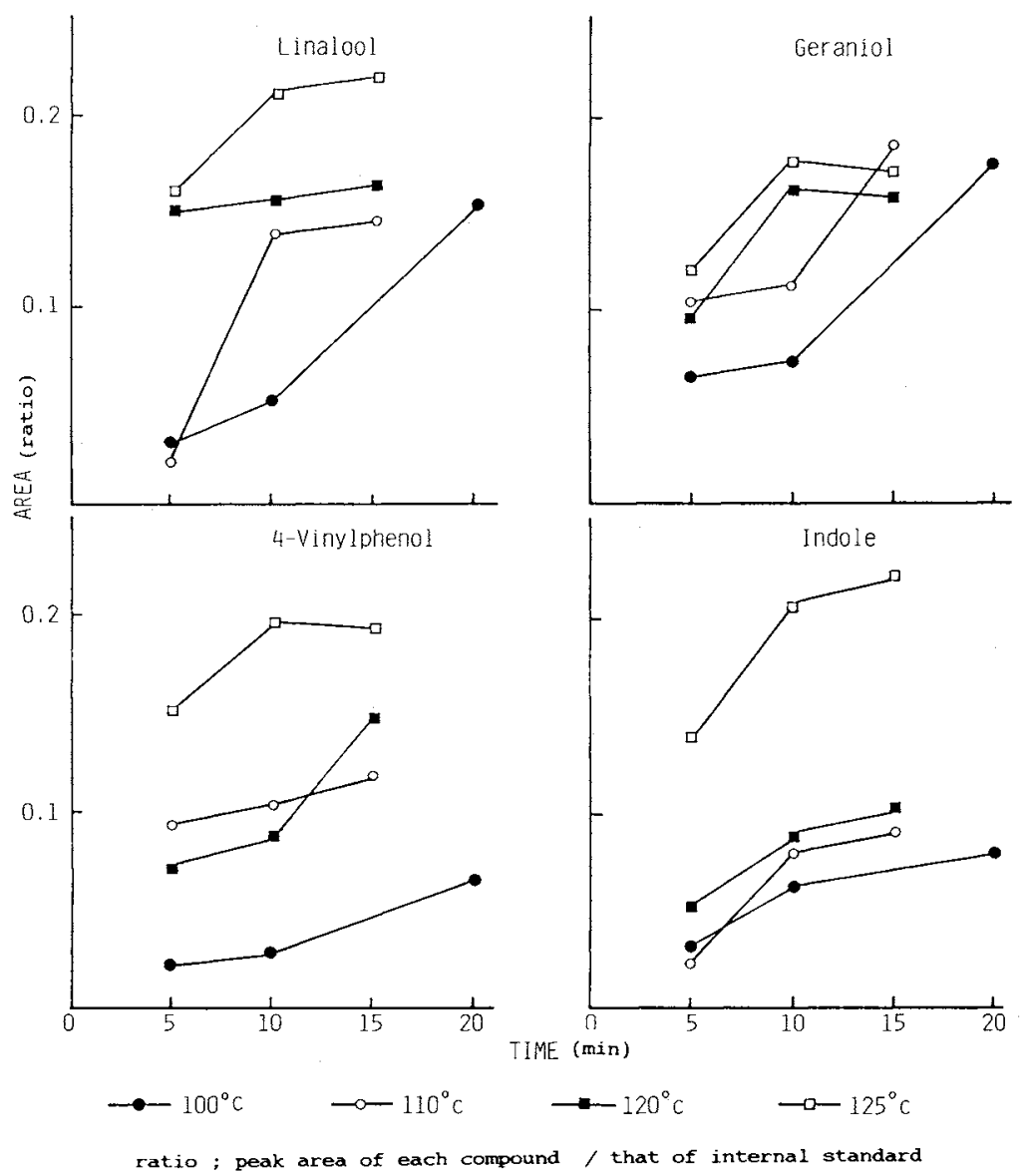

Fig. 1. Quantitative Changes of Linalool, Geraniol, 4-Vinylphenol and Indole in the Aroma Compounds of Green Tea Infusions after Retort Pasteurization at Different Temperatures.

With pasteurization temperatures between 100 and $120^{\circ} \mathrm{C}$, the amounts of those compounds increased with increasing pasteurization time.

3. Liberation of volatile compounds from the green tea extract by pectinase

In Fig. 2, the result of a preliminary experiment by using pectinase is shown. The liberation of linalool and geraniol in the tea infusion reached the maximum level after $14-16 \mathrm{hr}$ of incubation with pectinase after adding $10 \mathrm{mg}$ of pectinase to an infusion made by $10 \mathrm{~g}$ of green tea.

As shown in Table II, hexanal, 1-penten-3-ol, 1-pentenol, (E)-2-hexenal, (Z)-3-hexenol, $(E, E)$-2,4-heptadienal, methyl salicylate, lin- alool, linalooloxides, geraniol, $(Z)$-jasmone, nerolidole and indole were liberated by the abovementioned enzymatic reaction in the green tea infusion.

As the pectinase used was not purified, it is considered that other enzymes may have been present in this enzyme preparation. Therefore, the inhibitory effects of $\mathrm{Hg}^{2+}$, an inhibitor of the hydrolysis enzyme, and $\mathrm{CN}^{-}$, an inhibitor of metal-containing oxidase, were tested.

In Table II, the inhibitory effects of $\mathrm{Hg}^{2+}$ and $\mathrm{CN}^{-}$on the formation of those compounds by pectinase are also summarized.

The liberation of hexanal, $(E)-2$ hexenal and (Z)-3 hexenol was inhibited by $\mathrm{Hg}^{2+}$ and $\mathrm{CN}^{-}$. The enzymatic induction of other compounds such as linalool, geraniol, nerolidol, methyl 


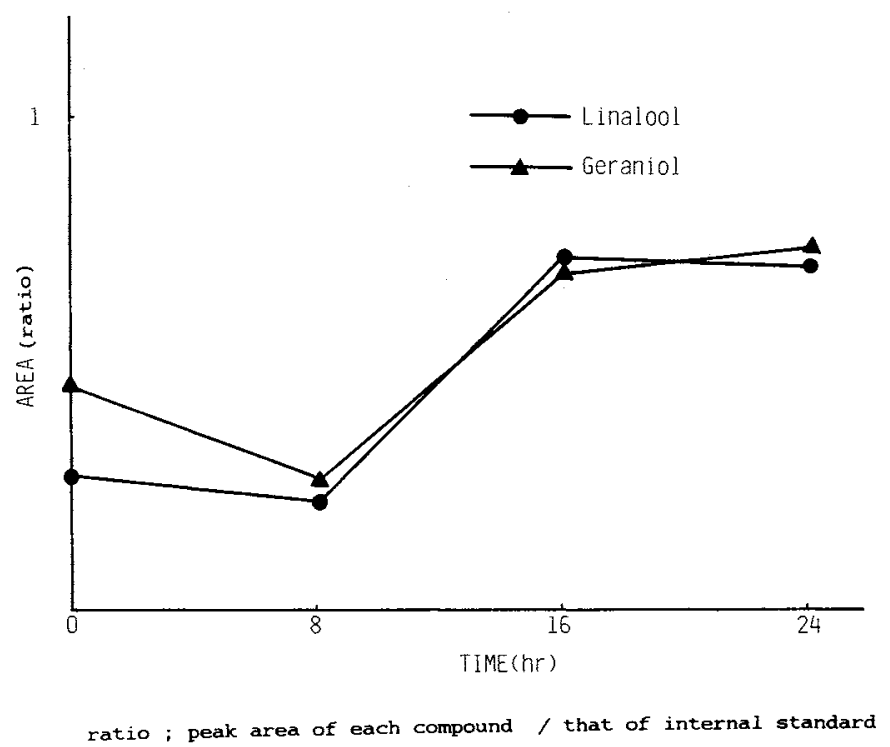

Fig. 2. Time Course of the Pectinase Reaction on the Liberation of Linalool and Geraniol in a Green Tea Infusion.

Amount of pectinase: $10 \mathrm{mg}$ in 11 of a green tea infusion made from $10 \mathrm{~g}$ of green tea.

Temperature: $38^{\circ} \mathrm{C}$.

The relative amounts of linalool and geraniol were assayed by $\mathrm{GC}$ from the aroma preparations of pectinase-reacted tea infusions.

salicylate, indole, $(Z)$-jasmone and jasminelactone was suppressed by $\mathrm{Hg}^{2+}$, while jasminelactone and indole were accelerated in the enzymatic formation by adding $\mathrm{CN}^{-}$. These results show that the liberation of volatile compounds found in a green tea infusion was induced by hydrolysis and oxidation with the added enzyme preparation from the nonvolatile compounds dissolved in the green tea infusion. It was also found that the liberation of some compounds was prompted by inhibiting the oxidative reaction.

\section{Discussions}

The formation mechanisms for tea aroma during the tea manufacturing process has been partially revealed. C-6 Alcohols (as leaf alcohol) and C-6 aldehyde (leaf aldehyde) have been produced from leaf lipid by enzymatic hydrolysis, oxidation, cleavage and reduction. ${ }^{5-9)}$ Linalool and geraniol were liberated from those glucosides accumulated in tea shoots by tea leaf glucosidase. ${ }^{10-12)}$ In tea shoots, linalool- $\beta$-D-glucopyranoside and gerniol- $\beta$-D-glucopyranoside have also been identified. ${ }^{3,13)}$

It is known that almost all parts of the precursors of tea aroma compounds are consumed and changed to volatile compounds by enzymatic reactions during fermentation in oolong and black tea. However, green tea is produced after the inactivation of endogenous enzymes in fresh leaves by steaming and by chemical compounds, which includes the precursors of tea aroma compounds in fresh shoots that are unchanged in made tea.

Therefore, it is thought that, in oolong and black tea, the water-soluble compounds changing to volatile compounds are negligible in the hot-water infusion. On the other hand, some water-soluble precursors of volatile compounds are dissolved in a green tea infusion. It is considered that the increase of the amounts of mono-terpene alcohols originates from the hydrolysis of those glucosides dissolved in a green tea infusion at temperatures over $100^{\circ} \mathrm{C}$. Regarding oolong and black 
Table II. INHIBITORy EFFects of Hg AND CN ON the Formation of Aroma Compounds in a Green tea Infusion by Pectinase

\begin{tabular}{|c|c|c|c|c|}
\hline \multirow[b]{2}{*}{ Compound } & \multirow{2}{*}{$\begin{array}{l}\text { Control } \\
\text { relative- } \\
\text { amount }^{a}\end{array}$} & \multicolumn{3}{|c|}{ Effects of pectinase ${ }^{b}$} \\
\hline & & Enzyme $^{c}$ & $\begin{array}{l}\text { With } \\
\mathrm{Hg}^{2+} \\
10^{-} \mathrm{M}\end{array}$ & $\begin{array}{l}\text { With } \\
\mathrm{CN}^{-} \\
10^{-} \mathrm{M}\end{array}$ \\
\hline 1-Penten-3-ol & $0.010(1)$ & 3.1 & 1.4 & 5.9 \\
\hline 1-Pentanol & $0.022(1)$ & 4.0 & 0.9 & 4.0 \\
\hline Hexanal & $0.065(1)$ & 1.7 & 0.2 & 0.9 \\
\hline (E)-2-Hexanal & $0.030(1)$ & 1.5 & 2.1 & trace \\
\hline (Z)-3-Hexenol & $0.099(1)$ & 1.0 & 0.4 & 0.5 \\
\hline Methyl salicylate & $0.019(1)$ & 1.2 & 0.7 & 1.7 \\
\hline $\begin{array}{l}(E, E)-2,4- \\
\text { Heptadienal }\end{array}$ & $0.100(1)$ & 1.5 & 1.0 & 2.7 \\
\hline Linalool & $0.367(1)$ & 1.4 & 0.8 & 1.6 \\
\hline Geraniol & $0.117(1)$ & 1.8 & 0.2 & 1.8 \\
\hline Nerolidol & $0.144(1)$ & 4.5 & 0.4 & 4.2 \\
\hline (Z)-Jasmone & $0.054(1)$ & 4.2 & 0.8 & 5.4 \\
\hline Jasminelactone & $0.049(1)$ & 2.5 & 0.8 & 8.2 \\
\hline Indole & $0.071(1)$ & 1.8 & 0.6 & 4.8 \\
\hline
\end{tabular}

Control, the original green tea infusion.

a The relative amount of each aroma compound to the internal standard in the original green tea infusion.

$b$ The inhibitory and activation ratio for the formation of aroma compounds by pectinase without and with the inhibitor. (Peak area of each compound in the green tea infusion treated by pectinase without and with inhibitors/peak area in the original infusion.)

$c$ Enzyme: Tea infusion treated by pectinase without inhibitors. (10 $\mathrm{mg}$ of pectinase was added in 11 of tea infusion made from $10 \mathrm{~g}$ of green tea and the infusion was incubated for $16 \mathrm{hr}$ at $38^{\circ} \mathrm{C}$.)

$\mathrm{Hg}^{2+}$ and $\mathrm{CN}^{-}$: Tea infusion treated by pectinase with each inhibitor.

teas, such phenomea are rarely found because those glucosides dissolve very little in the tea infusions.

Other compounds increased by retort pasteurization such as 4 -vinylphenol, $\beta$-ionone and indole may be liberated from $p$-coumaric acid and unknown precursors dissolved in the green tea infusion by hydrolysis under a high-temperature conditions.

C-6 Alcohol and aldehydes were also induced by pectinase. The formation of the glucosides of these compounds has been assumed in injured tissues. ${ }^{3)}$ However, as the enzymatic formation of these compounds was inhibited by $\mathrm{Hg}^{2+}$ and $\mathrm{CN}^{-}$, these compounds may be not produced from the glucosides. It is thought that these compounds have been induced from a small quantity of leaf lipid in the green tea infusion by the hydrolysis and oxidative reactions of coexisting enzymes in the pectinase preparation that was used.

However, no formation of hexanal, hexenal and hexenol was recognized after retort pasteurization. The leaf lipid may have not been coverted into small molecular compounds under retort pasteurization conditions, or the hexanal, hexenal and hexenol produced may have been destroyed during the pasteurization process.

From these results, it is thought that the origins of the off-flavor in tea drinks due to retort pasteurization may be induced by the two factors. The first is a deterioration of unstable aroma compounds such as leafalcohol and its esters by retort pasteurization, as was shown in the oolong and black tea infusions. The other is the liberation of volatile compounds from non-volatile precursors such as linalool and geraniol that are found in a green tea infusion.

Those phenomena may destroy the tea aroma balance and be the cause of the off-flavor tasted in tea drinks.

\section{References}

1) T. Yamanishi, M. Nose and Y. Nakatani, Agric. Biol. Chem., 36, 1153 (1972).

2) T. Yamanishi, M. Kawatatsu, T. Yokoyama and Y. Nakatani, Agric. Biol. Chem., 37, 1075 (1973).

3) N. Fisher, S. Nitz and F. Drawert, Z. Lebensm. Unter Forsch., 185, 195 (1987).

4) H. Kinugasa and T. Takeo, Nippon Nögeikagaku Kaishi, 63, 29 (1989).

5) A. Hatanaka, T. Kajiwara and J. Sekiya, Phytochemistry, 15, 1135 (1976).

6) A. Hatanaka, J. Sekiya and T. Kajiwara, Phytochemistry, 15, 487 (1976).

7) A. Hatanaka, T. Kajiwara, T. Koda and M. Murakami, Agric. Biol. Chem., 43, 2115 (1979).

8) A. Hatanaka, T. Kajiwara, J. Sekiya, M. Murakami and S. Inoue, Plant \& Cell Physiol., 23, 91 (1982).

9) J. Sekiya and A. Hatanaka, J. Agric. Food Chem., 20, 183 (1982).

10) T. Takeo, Phytochemistry, 20, 2145 (1981).

11) T. Takeo, J. Sci. Food Agric., 35, 84 (1984). 
12) T. Takeo, T. Tsushida, P. K. Mahanta, M. Tashiro and Y. Imamura, Bulletin of National Research Institute of Tea, No. 20, 91 (1985).
13) N. T. Skobeleva, T. P. Petrova and M. A. Bokuchava, Abstracts of Papers, International Tea Symposium in Rize, Turkey, 1987, p. 141. 